\title{
PEMBUATAN EMPING DARI BIJI RAMBUTAN
}

\author{
I.A.K Pramushinta ${ }^{1)}$, P.S. Ajiningrum ${ }^{2}$, Ngadiani $^{3)}$ \\ ${ }^{1}$ FSK, Universitas PGRI Adi Buana Surabaya \\ ${ }^{2,3}$ FST, Universitas PGRI Adi Buana Surabaya \\ email: iak.pramushinta@unipasby.ac.id,puritysabila@unipasby.ac.id,ngadiani@unipasby.ac.id
}

\begin{abstract}
Abstrak
Buah rambutan merupakan buah yang seringkali diminati masyarakat, biji rambutan mengandung polifenol dan senyawa golongan flavonoid yang berhasil diisolasi dari ekstrak etanol biji rambutan. Senyawa fenolik yang terdapat dalam ekstrak biji rambutan merupakan senyawa yang berperan dalam aktivitas antioksidan dan antibakteri. Pembuatan emping dari biji rambutan dengan cara diambil biji buah rambutan dan dicuci, biji rambutan disangrai matang sampai kulit mengelupas kemudian ditumbuk hingga pipih dan halus sampai membentuk bulatan pipih kemudian biji rambutan di ditumbuk dan dijemur selama 2 hari di bawah panas matahari, digoreng untuk siap dinikmati. Hasil yang dicapai dapat memberikan informasi kepada masyarakat bahwa manfaat emping biji rambutan baik untuk dikonsumsi oleh masyarakat.
\end{abstract}

Kata Kunci : Emping, Biji Rambutan

\section{Abstract}

\section{Making Rambutan Seed Chips}

Rambutan fruit is a fruit that is often in demand by the public, rambutan seeds contain polyphenols and flavonoid class compounds that have been isolated from the ethanol extract of rambutan seeds. The phenolic compounds contained in rambutan seed extract are compounds that play a role in antioxidant and antibacterial activity. Making chips from rambutan seeds by taking rambutan seeds and washing, roasting rambutan seeds until the skin peels off then pounding them until they are flat and smooth until they form flat spheres then pounded rambutan seeds and dried in the sun for 2 days under the hot sun, fried to be ready to enjoy. The results achieved can provide information to the public that the benefits of rambutan seed chips are good for consumption by the community.

Keyword : Chips, Rambutan Seeds

\section{PENDAhUlUaN}

Buah rambutan adalah buah yang umum dikenal oleh masyarakat Indonesia. Pohon rambutan yang sudah berbuah akan sangat menarik perhatian karena menghasilkan banyak buah yang bewarna merah. Selain buahnya yang manis dan mengandung banyak serat, biji rambutan juga memiliki banyak manfaat. Biji rambutan seringkali tidak diminati masyarakat karena bagian terluar dari biji rambutan dilapisi oleh kulit yang bertekstur keras seperti kayu tipis [1]. Seiring perkembangan ilmu pengetahuan, banyak penelitian yang membuktikan tentang manfaat biji rambutan. Biji rambutan mengandung polifenol [1]. dan beberapa senyawa golongan flavonoid yang telah berhasil diisolasi dari ekstrak etanol biji rambutan [4]. Berdasarkan penelitian senyawa fenolik yang terdapat dalam ekstrak biji rambutan merupakan senyawa yang berperan dalam aktivitas antioksidan dan antibakteri [4-5]. Kandungan 
senyawa fenolik dan flavonoid yang ditemukan pada tanaman dapat beraktivitas sebagai antioksidan [1-2]. Penelitian membuktikan bahwa tingginya senyawa fenolik dan flavonoid dari beberapa tanaman menunjukkan aktivitas antioksidan yang kuat [3]. Penelitian juga menunjukkan bahwa semakin tinggi kadar senyawa fenolik dan flavonoid maka aktivitas penangkap radikalnya semakin meningkat [2-3].

Isu permasalahan yang ada di masyarakat, banyak masyarakat memiliki tanaman rambutan yang ditanam di pekarangan warga tetapi masyarakat kurang terampil dan mengambil sisi positif dari ditanamnya tanaman tersebut sehingga kurang adanya pengetahuan tentang pemanfaatan buah rambutan terutama bijinya. Biji rambutan memiliki bermacam manfaat sehingga biji rambutan tersebut di buat menjadi emping agar memiliki nilai jual.

Tujuan dari penelitian ini diharapkan masyarakat dapat memanfaatkan hasil limbah dari buah rambutan yang ada sehingga menjadi produk yang siap dijual untuk meningkatkan taraf ekonomi masyarakat.

\section{KAJIAN LITERATUR DAN PENGEMBANGAN HIPOTESA}

Biji buah rambutan memiliki banyak manfaat yang digunakan sebagai obat dalam berbagai penyakit yaitu diabetes, radang lambung. Kandungan biji buah rambutan banyak mengandung polifenol dan beberapa senyawa golongan flavonoid yang telah berhasil diisolasi dari ekstrak etanol biji rambutan. Dari berbagai macam manfaat yang dimiliki oleh biji rambutan maka seharusnya masyarakat dapat memanfaatkan hasil limbah biji rambutan sebagai nilai jual yang dapat meningkatkan perekonomian masyarakat.

\section{METODE PENELITIAN}

Pelaksanaan pembuatan emping biji rambutan di program studi biologi Fakultas Sains
Teknologi Universitas PGRI Adi Buana Surabaya. Alat dan Bahan yang digunakan biji rambutan, penggorengan, minyak, palu. Pelaksanaan pembuatan emping biji belinjo dengan memberikan pegarahan dan praktek langsung dapat dilihat pada Gambar 1.
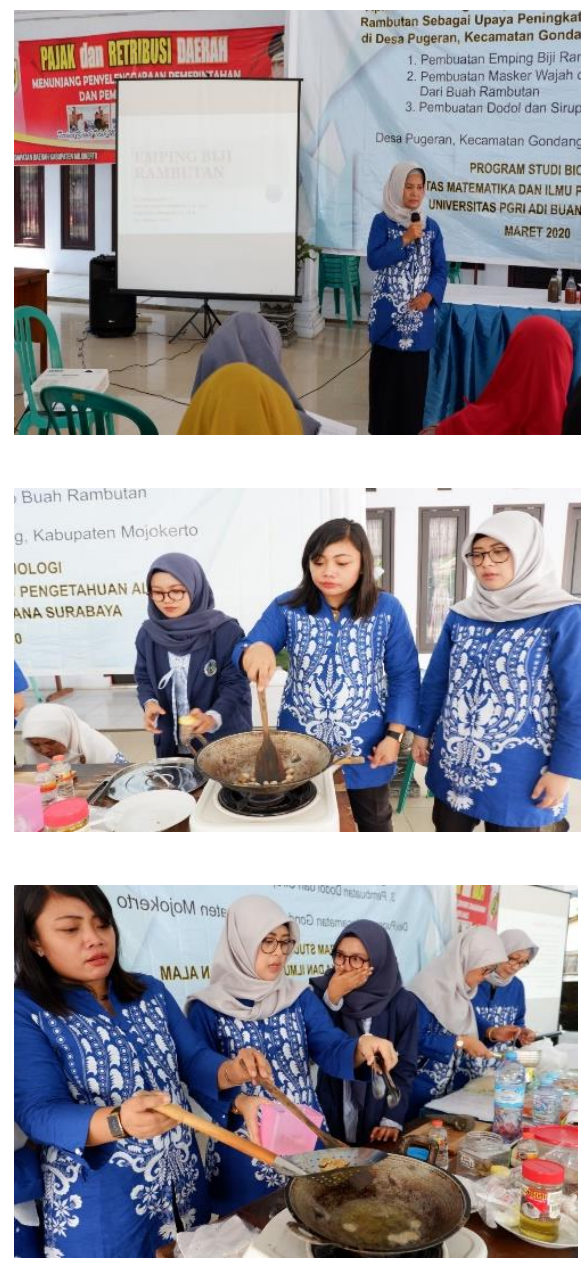

Gambar 1. Pelaksanaan pembuatan emping biji rambutan

Pada Gambar 1 melakukan kegiatan PPM di desa Pugeran kecamatan Gondang Kabupaten Mojokerto melakukan penjelasan dan praktek pelaksanaan untuk pembuatan emping biji rambutan.

Metode yang dilaksanakan untuk pembuatan emping biji rambutan yaitu biji buah rambutan sebanyak $1 / 2$ kilogram kemudian di sangrai pada penggorengan hingga kulit biji buah rambutan mengelupas, ditumpuk hingga pipih dengan 
menggunakan palu dan dijemur di bawah sinar matahari kurang lebih 2 hari kemudian digoreng sampai warna kecoklatan dan siap untuk di hidangankan dengan ditambahakan berbagai aneka rasa misalkan balado, spicy, asin dan manis. Hasil pembuatan emping biji rambutan pada Gambar 2.
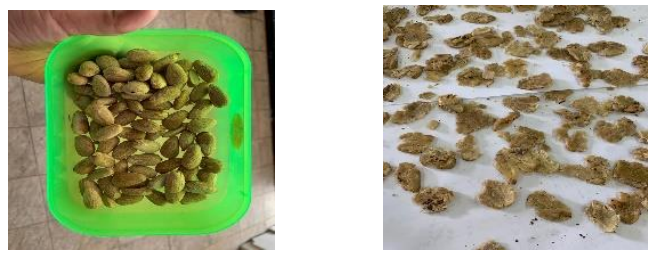

Gambar 2. Proses pembuatan emping biji rambutan

\section{HASIL DAN PEMBAHASAN}

Hasil yang di dapatkan berupa biji buah rambutan yang diolah menjadi sebuah makanan atau camilan yaitu emping. Emping yang berbahan dasar dari biji rambutan dengan di tambah berbagai toping bumbu diatasnya sehingga menambah selera makan untuk para penggemarnya.

\section{KESIMPULAN}

Kesimpulan dari kegiatan pelatihan pembuatan emping dari biji buah rambutan adalah pelaksanaan kegiatan berjalan dengan baik dan lancar berkat antusias peserta dan penjelasan materi oleh tim Dosen Biologi FMIPA juga dapat dipahami dengan baik oleh peserta.

\section{REFERENSI}

1. Dalimartha. 2005. Atlas Tumbuhan Obat Indonesia, Jilid 3. Puspa Swara, Jakarta.

2. Hernani dan Raharjo, M., 2006. Tanaman Berkhasiat Antioksidan, Penebar Swadaya, Jakarta.

3. Maisuthisakul, P., Pasuk, S., and Ritthiruangdej, P. 2007. Relationship Between Antioxidant Properties and Chemical Composition of Some Thai
Plants, Journal of Food Composition and Analysis, 21, 229-240.

4. Asrianti, M., Ruslan, K., dan Nawawi, A. 2006. Telaah Fitokimia Biji Rambutan (Nephelium lappaceum L.), Skipsi. Farmasi Institut Teknologi Bandung.

5. Thitelerdecha, N., Teerawutgulrag, A., and Rakariyatham, N. 2008. Antioxidant and Antibacterial Activities of Nephelium lappaceum L. Extracts, Food Science and Technology. 41: 2029-2035 